\title{
ROLE OF BARIUM ENEMA IN THE DIAGNOSIS OF HIRSCHSPRUNG DISEASE
}

\author{
Ch. Deepak Singh ${ }^{1}$, Rajib Ray Baruah ${ }^{2}$
}

${ }_{1}^{1}$ MCh Trainee, Department of Paediatric Surgery, Gauhati Medical College \& Hospital, Guwahati. ${ }^{2}$ Assistant Professor, Department of Paediatric Surgery, Gauhati Medical College \& Hospital, Guwahati.

\section{ABSTRACT}

Hirschsprung Disease (HD) is a common cause of neonatal intestinal obstruction, a congenital malformation of the enteric nervous system characterised by aganglionosis of the distal bowel leading to neonatal large gut obstruction and clinical constipation.

\section{AIM}

The aim of my study is to assess the efficacy of barium enema as a simple radiological study in diagnosing HD.

\section{MATERIALS AND METHODS}

Fifty four (54) cases of suspected HD (Clinically) were studied over 24 months (Feb. 2014 to Jan. 2016). Barium enema study was carried out.

\section{RESULTS}

The results were statistically analysed, $81.5 \%$ cases were diagnosed as HD by barium enema study.

\section{CONCLUSIONS}

Barium enema is a simple and primary study for the diagnosis of Hirschsprung disease and helps in accurate planning for type of surgery preoperatively.

\section{KEYWORDS}

Barium Enema, Aganglionosis, Hirschsprung Disease.

HOW TO CITE THIS ARTICLE: Singh CD, Baruah RR. Role of barium enema in the diagnosis of Hirschsprung disease. J. Evolution Med. Dent. Sci. 2016;5(72):5245-5248, DOI: 10.14260/jemds/2016/1188

\section{INTRODUCTION}

Hirschsprung Disease (HD) is a developmental disorder characterised by the absence of ganglion cells in the myenteric and submucosal plexuses of the distal intestine resulting in functional obstruction. Since it is caused by premature arrest of the migration of neural crest cells along the hindgut, it is also defined as neurocristopathy. ${ }^{[1]}$

Although, this condition was described by Fredericus Ruysch in 1691 and popularized by Harald Hirschsprung in 1886, the pathophysiology was not clearly determined until the middle of the 20th century, when Whitehouse and Kernohan described the aganglionosis of the distal intestine as the cause of obstruction in their series of 11 patients who died of megacolon, published in 1948.[2]

The neonate with HD is usually a full-term baby and presents with a distended abdomen, feeding intolerance with bilious aspirate or bilious vomiting and classically with delay in the passage of meconium. Delayed passage of meconium beyond the first 24 hours is characteristic and is present in approximately $90 \%$ of children with HD.

The three most popular investigations for Hirschsprung disease are barium enema, histological study and anorectal manometry. However, the histological study remains the gold standard using paraffin-embedded biopsies.[3]

Financial or Other, Competing Interest: None.

Submission 25-07-2016, Peer Review 22-08-2016,

Acceptance 30-08-2016, Published 06-09-2016.

Corresponding Author:

Dr. Ch. Deepak Singh,

MCh Trainee,

Department of Paediatric Surgery,

GMCH, Guwahati, Kamrup Metro-781032.

E-mail: chingtham@yahoo.co.in

DOI: $10.14260 /$ jemds/2016/1188

\section{(c) (1) $(9)$}

The definitive finding that defines Hirschsprung disease is absence of ganglion cells in the submucosal and myenteric plexuses in an adequate biopsy specimen of the rectum located more than $2 \mathrm{~cm}$ above the pectinate line. Most patients will also have evidence of hypertrophied nerve trunks, although this finding is not always present, particularly in children with total colonic disease or a short aganglionic segment. [4]

Barium enema is a non-invasive investigation available for the surgeon to assess the level of aganglionosis and plan the corrective surgery. Though radiological transition zone is evidenced to be the most reliable sign to evaluate the level of aganglionosis, some studies fail to show matching result of aganglionosis by histopathology.[5]

Although classic radiographic findings of Hirschsprung disease are a narrow, spastic distal intestinal segment with a dilated proximal segment, rectal or colonic biopsies are essential for definitive diagnosis and to define the level of aganglionosis. The pathognomonic finding of Hirschsprung disease on contrast enema is a transition zone between the normal and aganglionic bowel, although approximately $10 \%$ of neonates with Hirschsprung disease may not have a demonstrable radiologic transition zone.[1]

\section{MATERIALS AND METHODS}

Approval for this study was obtained from our Institutional Ethics Committee. This was a prospective observational study carried out in Gauhati Medical College and Hospital in the Department of Paediatric Surgery from February 2014 to January 2016. Barium enema was carried out in the Department of Radiology, Gauhati Medical College and Hospital, Guwahati.

\section{Inclusion Criteria}

All the patients admitted in the Department of Paediatric Surgery or referred from allied departments suspected of 
having HD by clinical examination and history was taken in the study. Children above 14 years of age were excluded from the study. In total fifty four patients were selected for the study.

\section{Contrast Enema Technique}

Before contrast enema study, plain X-ray abdomen was taken in supine and erect postures. Then, a soft rubber catheter of appropriate size was inserted just into the anal opening and secured in position with firm strapping drawn tightly across the buttocks by adhesive plaster. The patients were kept in the lateral position. In neonates with suspected intestinal obstruction of uncertain aetiology, water soluble contrast material (Anhydrous Diatrizoic acid $597.3 \mathrm{mg} / \mathrm{mL}$, Meglumine $159.24 \mathrm{mg} / \mathrm{mL}$ ) was used. In other cases of suspected Hirschsprung disease, barium suspension diluted $50 \%$ with normal saline was injected slowly. The contrast material was instilled with $50 \mathrm{~mL}$ syringe, slowly under fluoroscopic guidance. Once the contrast material started to funnel up, $\mathrm{X}$ rays were taken till it clearly outlined the distended proximal normal ganglionic colon. Occasionally, repeat films at 24 hours were taken in equivocal cases. Rectal wash was done with warm normal saline after the procedure.

\section{Statistical Analysis}

We used GraphPad InStat (GraphPad Software Inc. 5755 Oberlin Drive \#110, San Diego, CA 92121, USA) for the statistical analysis and included descriptive statistics for the demographic variables.

\section{RESULTS AND OBSERVATION}

Fifty four cases were included in our study and the results and observations of the data were recorded in tables, bar and pie diagram which were statistically calculated and presented.

\begin{tabular}{|c|c|c|}
\hline Age in Years & No. of Patients & $\%$ \\
\hline 1-6 Months & 20 & 37.0 \\
\hline 6-12 Months & 12 & 22.2 \\
\hline 12-24 Months & 10 & 18.5 \\
\hline $24+$ Months & 12 & 22.2 \\
\hline Total & 54 & 100.0 \\
\hline
\end{tabular}

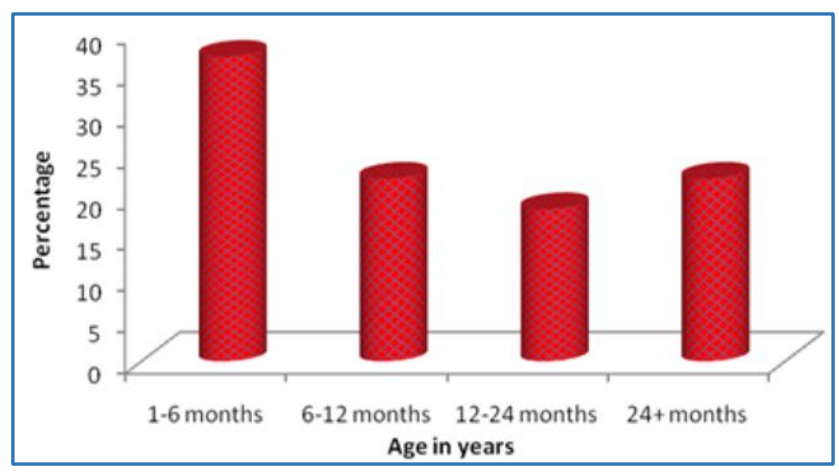

\section{Observation}

Maximum cases were seen in 1-6 months (37\%) followed equally by two groups 6-12 months and $>24$ months (22.2\%) in this present study.

\begin{tabular}{|c|c|c|}
\hline Gender & No. of Patients & \% \\
\hline Female & 14 & 25.9 \\
\hline Male & 40 & 74.1 \\
\hline Total & $\mathbf{5 4}$ & $\mathbf{1 0 0 . 0}$ \\
\hline \multicolumn{2}{|c|}{ Table 2: Gender Distribution of Patients Studied } \\
\hline
\end{tabular}

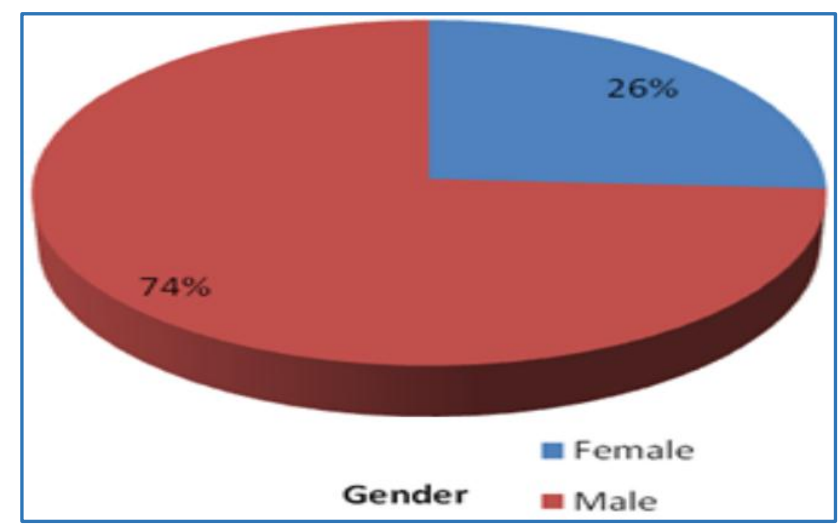

Observation: Ratio of male-to-female is 2.8:1.

\begin{tabular}{|c|c|c|}
\hline $\begin{array}{c}\text { Clinical } \\
\text { Manifestations }\end{array}$ & $\begin{array}{c}\text { In } \\
\text { Neonates }\end{array}$ & $\begin{array}{l}\text { In Remaining } \\
\text { Patients }\end{array}$ \\
\hline DPM & $5(83.3 \%)$ & $0(0 \%)$ \\
\hline Abdominal Distension & $1(16.7 \%)$ & $9(33.3 \%)$ \\
\hline Vomiting & $0(0 \%)$ & $3(11.1 \%)$ \\
\hline Constipation & $0(0 \%)$ & $12(44.5 \%)$ \\
\hline Others & $0(0 \%)$ & $3(11.1 \%)$ \\
\hline Total & $6(100 \%)$ & $27(100 \%)$ \\
\hline \multicolumn{3}{|c|}{$\begin{array}{l}\text { Table 3: Frequency of Different Clinical Manifestations } \\
\text { of Patients with Hirschsprung Disease according to Age }\end{array}$} \\
\hline
\end{tabular}

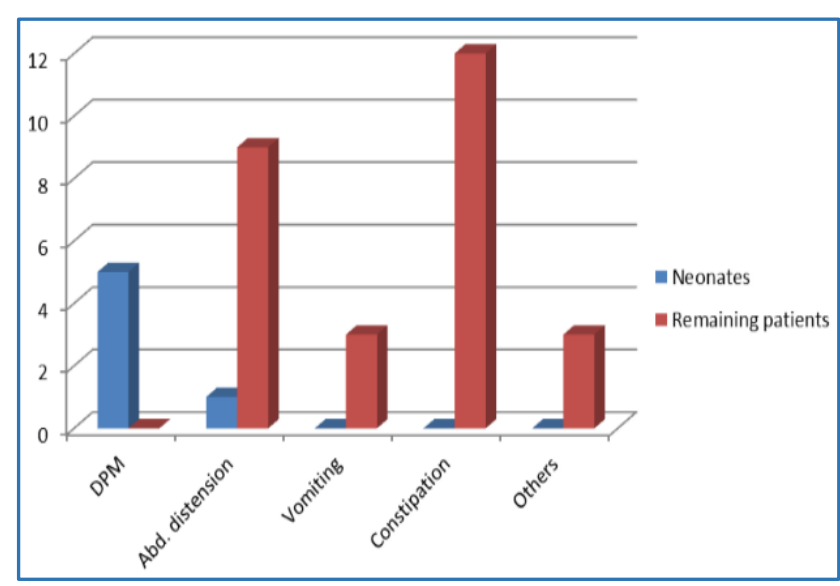

\section{Observation}

The neonates commonly presented with delayed passage of meconium [DPM] (83.3\%) followed by abdominal distension $(16.7 \%)$. In remaining patients, constipation $(44.5 \%)$ was the most common clinical manifestation.

\begin{tabular}{|c|c|c|}
\hline Barium Enema & No. of Patients & $\%$ \\
\hline Hirschsprung Disease & 44 & 81.5 \\
\hline Non-Hirschsprung Disease & 10 & 18.5 \\
\hline Total & 54 & 100.0 \\
\hline \multicolumn{3}{|c|}{ Table 4: Barium Enema Finding } \\
\hline
\end{tabular}




\section{Barium Enema Finding}

Observation: $81.5 \%$ were detected by radiological examination as a case of HD.

\section{DISCUSSION}

Hirschsprung disease is a relatively common cause of intestinal obstruction in the new-born. The average age at the time of diagnosis has been decreasing over the years. It is characterised by absence of ganglionic cells in the distal bowel beginning at the internal sphincter and extending proximally for varying distances. The aganglionosis is confined to rectosigmoid in $75 \%$ of patients, the sigmoid, splenic flexure or transverse colon in $17 \%$ and total colon along with a short segment of terminal ileum in $8 \%$ of patients.[6]

The characteristic gross pathological feature in Hirschsprung disease is dilation and hypertrophy of the proximal colon with abrupt or gradual transition to normal or narrow distal bowel. Although the degree of dilation and hypertrophy increases with age, the cone-shaped transitional zone from dilated to narrow bowel is usually evident in the newborn. Histologically, Hirschsprung disease is characterised by the absence of ganglionic cells in the myenteric and submucous plexuses and the presence of hypertrophied non-myelinated nerve trunks in the space normally occupied by the ganglionic cells. The aganglionic segment of bowel is followed proximally by a hypoganglionic segment of varying length. This hypoganglionic zone is characterised by a reduced number of ganglionic cells and nerve fibers in myenteric and submucous plexuses.

Delineation of the transition zone by contrast enema in Hirschsprung disease needs to be regarded with caution. This is especially true in long-segment disease, where knowledge of the extent of aganglionic bowel is most crucial for surgical planning. Also, the level of radiological transition zone may not correlate with the actual level of transition zone confirmed by histopathology. As per Jamieson DH et al contrast enema used for the diagnosis of Hirschsprung disease has a reported falsenegative rate between $20 \%$ and $25 \%$, and false-positive identification of a transition zone reported as high as $43 \% .{ }^{[7]}$

Barring exceptions the radiologic, gross and histological transition zone generally corroborate in rectosigmoid Hirschsprung disease and do not pose problems in identifying the distal limit of normally innervated colon for a temporary colostomy or a definitive pull through.[8]

As mentioned earlier, barium enema is a non-invasive investigation available for the surgeon to assess the level of aganglionosis and plan the corrective surgery. Though radiological transition zone is evidenced to be the most reliable sign to evaluate the level of aganglionosis, some studies fail to show matching result of aganglionosis by histopathology.[5]

The radiologic transition zone is clearly identifiable in the majority of contrast enemas in rectosigmoid Hirschsprung disease and usually extends proximally over a few centimetres, maximally till the proximal sigmoid. This relationship is so constant that many centres in developing countries like ours, which lack facilities for intraoperative histological levelling continue to perform surgical procedures (Colostomy/pull through) based on the radiological transition zone.[8]
Jamieson DH et al[7] conducted their study on 32 patients of Hirschsprung disease who had short segment disease in 24 (75\%) patients. They concluded that 18 (75\%) patients had concordance between radiology and pathological finding.

Another study done by Proctor ML et al[9] has noted that in rectosigmoid Hirschsprung disease, the location of the radiographic transition zone correlates accurately with the level of aganglionosis in nearly $90 \%$.

In another study done by Pratap A et al[10] in 27 patients, the transition zone was located at rectosigmoid in 14 (78\%), midsigmoid in 2 (11\%) and descending colon in 2 (11\%). Of the 18 patients showing transition zone, $13(72 \%)$ had a matching level of aganglionosis by histopathological correlation. Contrast enema failed to reveal a transition zone in 9 out of 27 (33\%) patients. The overall accuracy of contrast enema transition zone concordant to the pathological level of aganglionosis was $72 \%$.

As per a study done by Das K et al,[8] 95.4\% (104/109) of their cases of rectosigmoid Hirschsprung disease had a definite radiologic transition zone on the contrast enema. There was a near total concordance between the radiographic transition zone and the histologic transition zone (96.2\%) and the histologic transition zone extended maximally till the sigmoid-descending colon junction.

In the series of Granero CR et al,[11] transition zone could be seen in $90 \%$ of the cases with barium enema, its most common location was rectosigmoid. After statistical analysis, the length measured at radiology tests and the length of the anatomic piece showed a variable correlation being highest for rectosigmoid transition and very low values for long affected segments.

Hence, the radiographic transition zone and the histologic transition zone generally coincide in the classic rectosigmoid Hirschsprung disease and the surgeon who solely depends on the contrast enema for deciding the level of colostomy/pull through without a histopathological intraoperative levelling will still be correct in his management in the majority.[8]

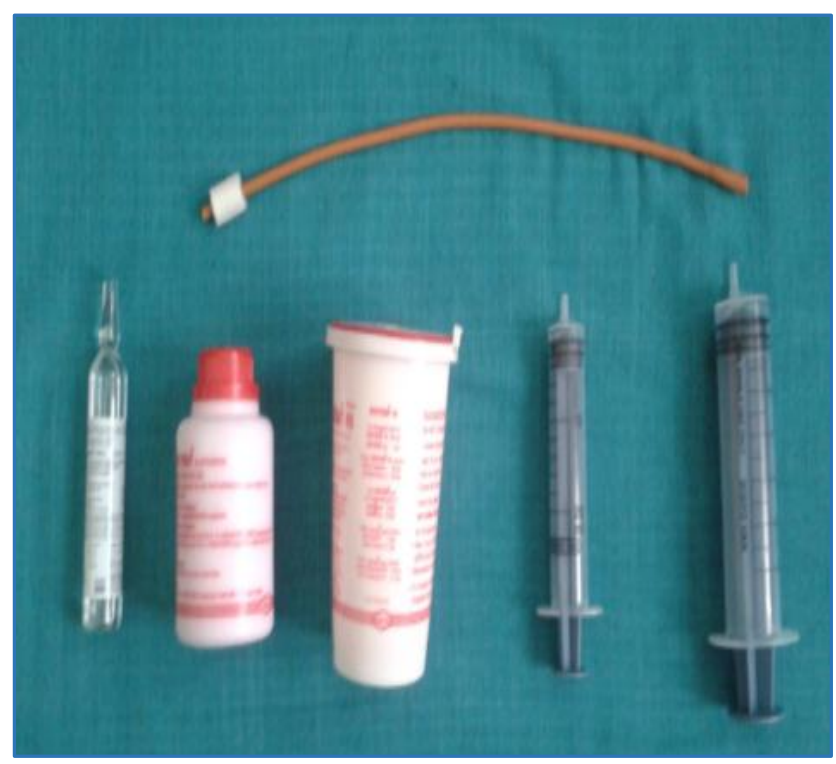

Fig. 1: Materials used for Contrast Enema. Rubber Catheter 


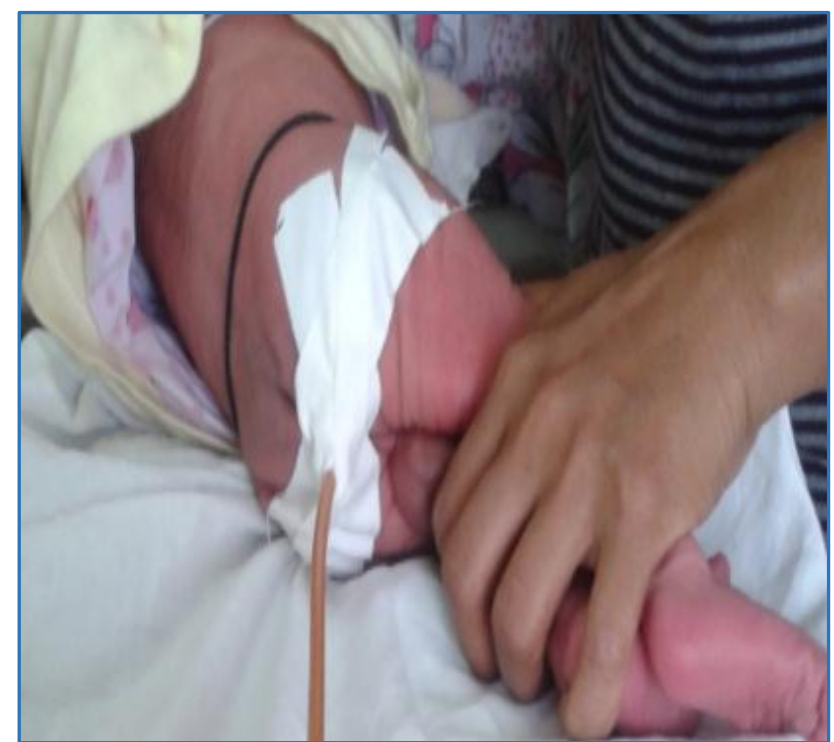

Fig. 2: Enema Technique. Buttocks are Tightly Strapped

Water soluble contrast material, barium solution and 20 $\mathrm{mL}$ and $50 \mathrm{~mL}$ syringes with adhesive tape. The catheter is secured with a loop of tape.

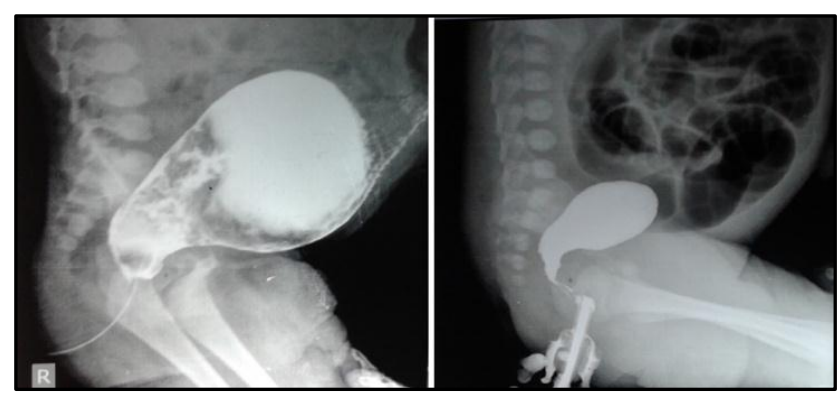

Fig. ( $a$ \& b): Contrast Enema. Transition Zone at Rectosigmoid Region, L5 in (a) \& S2 in (b)

\section{CONCLUSION}

Hirschsprung disease is a relatively common cause of intestinal obstruction in the paediatric age group. Barium enema provides a reliable diagnosis by detecting the dilated segment and the transition zone in the colon. So, a surgeon can decide the type of operation to be performed by radiological finding only without any histological examinations.
Thus, our results demonstrate that barium enema can be extremely useful in the diagnosis and pre-operative planning for surgery.

\section{REFERENCES}

1. Langer JC. Hirschsprung disease. Pediatric surgery. In: Coran AG, edr. 7th $^{\text {edn. Philadelphia: Elsevier Saunders }}$ 2012.

2. Hirschsprung H. Stuhltragheit neugeborner in folge von dilatation and hypertrophie des colons. Jahrbuch für Kinderheilkunde und physische Erziehung, Berlin. 1888;27:1-7.

3. De la Torre L, Santos K, Vargas-Gonzalez R. Hirschsprung disease. Evaluation of calretinin and S-100 as ancillary methods for the diagnosis of aganglionosis in rectal biopsies. Acta Pediátrica de México 2012;33(5):246-51.

4. Odze RD, Goldblum JR. Surgical pathology of the GI tract, liver, biliary tract and pancreas. $2^{\text {nd }}$ edn. Philadelphia: Saunders 2009:131-3.

5. Muller CO, Mignot $\mathrm{C}$, Belarbi $\mathrm{N}$, et al. Does the radiographic transition zone correlate with the level of aganglionosis on the specimen in Hirschsprung's disease? Pediatr Surg Int 2012;28(6):597-601.

6. Puri P. Hirschsprung's disease. Newborn surgery. In: Puri P, edr. 2nd edn. London: Hodder Arnold 2003.

7. Jamieson DH, Dundas SE, Belushi SA, et al. Does the transition zone reliably delineate aganglionic bowel in Hirschsprung's disease? Pediatr Radiol 2004;34(10): 811-5.

8. Das K, Kini U, Babu MK, et al. The distal level of normally innervated bowel in long segment colonic Hirschsprung's disease. Pediatr Surg Int 2010;26(6):593-9.

9. Proctor ML, Traubici J, Langer JC, et al. Correlation between radiographic transition zone and level of aganglionosis in Hirschsprung's diseases: implications for surgical approach. J Pediatr Surg 2003;38(5):775-8.

10. Pratap A, Gupta DK, Tiwari A, et al. Application of a plain abdominal radiograph transition zone (PARTZ) in Hirschsprung's disease. BCM Pediatrics 2007;7:5.

11. Cendón GR, Jiménez MMJ, García CR, et al. Relationship between the radiological length of the opaque enema and the aganglionic length of the segment in Hirschsprung's disease. Cir Pediatr 2010;23(1):53-6. 